\title{
Experiências e memórias: o trabalho com diários reflexivos
}

\author{
Experiences and memories: working with reflective diaries
}

\begin{abstract}
Alex Junior Bilhoto Faria ${ }^{1}$
\section{Resumo}

Este artigo apresenta a síntese reflexiva a respeito das experiências vivenciadas, por mim, enquanto jovem docente de Língua Portuguesa, durante o processo de entrada como professor no Ensino Superior, embasando-me no Sistema da Avaliatividade de Martin e White (2005), Vian Jr. (2010). Nessa perspectiva, as indagações iniciais são: a) quais foram as principais preocupações expostas nos diários? b) como essas preocupações se realizam linguisticamente? Para tanto, com base na teoria a respeito dos diários reflexivos, como uma produção intimista e reveladora dos fatos vivenciados, respaldo-me em Zabalza (1994) e Reichmann (2007). A metodologia utilizada para essa investigação é a da pesquisa qualitativa, por meio da elaboração de diários reflexivos; descrevendo ações relacionadas ao processo de seleção e as angústias existentes a partir desse. Telles (2002). Essa pesquisa faz-se necessária por investigar os fatores vivenciados em um novo contexto profissional e as implicações que podem ser causadas aos professores iniciantes. Espera-se, então, contribuir com os jovens docentes que anseiam lecionar no Ensino Superior, por meio da discussão sobre as incertezas e as inseguranças encontradas nesse processo. Dado isso, os resultados sinalizam como as relações sentimentais e de afeto estão conectadas à formação docente e, ainda, este artigo também pode servir de aporte para a reflexão crítica de textos autoavaliativos.
\end{abstract}

Palavras-Chave: identidade docente; diários reflexivos; formação de professores.

\section{Abstract}

This article presents the reflexive synthesis about the experiences lived by me, as a young teacher of Portuguese Language, during the admission process as a teacher in Higher Education, based on the Evaluative System of Martin and White (2005), Vian Jr (2010). From this perspective, the initial questions are: a) what were the main concerns exposed in the diaries? b) How do these concerns come about linguistically? To this end, based on the theory about reflexive diaries, as an intimate and revealing production of the facts I experienced, I support myself in Zabalza (1994) and Reichmann (2007). The methodology used for this investigation is based on qualitative research, through the elaboration of reflective diaries; describing actions related to the selection process and the existing anxieties from it. Telles (2002). This research is necessary to investigate the factors, which were experienced in a new professional context, and the implications that may be caused to novice teachers. It is expected to contribute to the novice teachers who yearn to teach in Higher Education, by discussing the uncertainties and insecurities found in this process. Considering it, the results indicate how sentimental and affectional relations are connected to teacher education, and this

\footnotetext{
${ }^{1}$ Mestre em Educação pela Universidade Federal de Lavras (UFLA/MG). Especialista em Docência do Ensino Superior (Faculdade Futura/ICETEC). Graduado em Letras (Fepi/MG). Professor no Centro Universitário do Sul de Minas. E-mail: alexbilhoto@gmail.com.
}

Revista Devir Educação, Lavras, vol.4, n.2, p.314-327 jul./dez., 2020. 
article can also serve as a contribution to the critical reflection of self-evaluative texts.

Keywords: teaching identity; reflective diaries; teacher training.

\section{Introdução}

A produção escrita é uma atividade humana encontrada em todas as manifestações verbais das diversas áreas do conhecimento, afinal, escrever é um mecanismo comunicativo de registro. Contudo, no quadro específico da formação docente, o professor em formação inicia a sua graduação sem o conhecimento efetivo de produções escritas sociais. Aliado a isso, de modo correspondente, uma vez já formado, o docente responsável por ministrar um número significativo de aulas, majoritariamente, pouco produz, limitando-se, nessa direção; a ser corretor de textos elaborados por alunos como informa Menegassi $(2003 ; 2011)$.

Nesse enfoque, retirando-se a conjuntura de corretor das produções textuais de alunos, contextualizo que a escrita científica, realizada obrigatoriamente em processos de formação inicial, não favorece, em sua completude, a elaboração de textos reflexivos, nos quais o sujeito introduza suas crenças, vontades, pensamentos, valores, angústias e outros como afirma Coracini (2010).

Outrossim, é nesse contexto que trago a importância da escrita reflexiva por meio da concepção de diários, sendo uma produção introspectiva do sujeito em relação às práticas vivenciadas por ele e as variadas interpretações obtidas a partir de ações. É nesse foco que Zabalza (2004, p.136) esclarece que "estamos tão entranhados no cotidiano, nessa atividade frenética que nos impede de parar para pensar, para planejar, para revisar nossas ações que o diário é uma espécie de oásis reflexivo".

Para este artigo, inserindo-se no bojo dos estudos sobre a formação do professor, e inscrevendo-se no projeto de pesquisa Identidade do Docente de Línguas (IDOLIN) ${ }^{2}$, a relação teórica direta é a correlação da formação docente por meio da investigação de diários reflexivos, produzidos por mim. Outros trabalhos acadêmicos promovem a discussão sobre a utilização dos diários reflexivos com fins pedagógicos, como exemplos: "Diários reflexivos e avaliação formativa: um olhar sobre a prática do professor" (SILVA, 2014), "Letramentos digitais e ensino-aprendizagem de língua inglesa: reflexões acerca do processo críticoreflexivo do aluno em sala de aula" (MAGALHÃES, 2018).

\footnotetext{
${ }^{2} \mathrm{O}$ projeto visa a discutir e refletir sobre o processo de construção da identidade do docente de línguas materna e adicionais, tendo como líder e vice-líder, respectivamente, as professoras: Tania R. S. Romero e Maria Eugenia Batista.
} 
A produção dos diários foi embasada na minha própria prática, enquanto professor de Língua Portuguesa, com 22 anos, do Ensino Superior Privado, no Sul de Minas Gerais, nos cursos de Administração e Ciências Contábeis, lecionando a disciplina de Comunicação e Expressão. Dentre as razões que fomentaram a produção dos textos reflexivos, encontram-se: a) a questão da pouca idade para lecionar no Ensino Superior b) o fato de não possuir pósgraduação concluída em nível Lato Sensu ou Stricto Sensu, c) os desafios encontrados nos momentos de aula ou de planejamento prévio.

Diante do exposto, as questões de pesquisa são: a) quais foram as principais preocupações expostas nos diários? b) como essas preocupações se realizam linguisticamente?

Para justificar esta discussão, reforço a importância de se refletir sobre a própria prática docente e os elementos constitutivos dessa, posto que é por meio da produção reflexiva que se torna possível investigar, de modo externo, as minhas atitudes e ações em sala de aula na interação com os alunos e outros atores educacionais.

Desse modo, por meio do uso dos diários reflexivos como recurso interpretativo e reflexivo das minhas ações, apresenta-se como teor principal a investigação de práticas docentes próprias por meio da análise de textos reflexivos dos momentos iniciais como professor de Língua Portuguesa no Ensino Superior Privado.

Para tanto, a reflexão teórica tem como base os autores: Halliday (1994), Martin \& White (2005), Vian Jr. (2010) como fundamentos conceituais relacionados à Linguística Sistêmico-Funcional e ao Sistema da Avaliatividade, respectivamente. Machado (1998), Zabalza (2004), Reichmann (2009) como referências temáticas para a apresentação dos elementos relacionados à produção de diários reflexivos.

Com fins organizacionais, a divisão das próximas partes do artigo se dá, inicialmente, por meio de discussão a respeito da produção dos diários reflexivos, da Linguística SistêmicoFuncional e do Sistema da Avaliatividade, em que me apoio para caracterização linguística dos dados. Seguem-se a explicitação dos aspectos metodológicos e a discussão dos dados. Termino por tecer considerações e reflexões sobre a pesquisa.

\section{A produção reflexiva: o trabalho com diários.}


Como contextualiza Machado (1998), a produção dos diários origina-se a partir do século XIX, com o objetivo de exteriorizar conflitos internos e reflexões pessoais, logo, é por essa razão que, a priori, faz-se necessário relacionar a escrita de diários com o processo reflexivo e de investigação da identidade profissional (TÁPIAS-OLIVEIRA, 2013). Para nós, do campo educacional na qualidade de docentes, tem-se essa produção com uma ferramenta de suporte que fomenta a reflexão posterior a ação (PORTER ET ALII, 1990) e, ainda, como uma forma de examinar a própria prática docente (DIAS, 2013).

Nesse contexto, é válido corroborar a visão de transformação histórica a respeito da formação do professor no Brasil, sendo um processo de mudança de perspectiva metodológica e formativa, entre os períodos das décadas de 80 e 90, em que

[...] os estudos sobre a formação do professor voltam-se crescentemente para a compreensão dos aspectos microssociais [sic], destacando e focalizando, sob novos prismas, o papel do agente-sujeito. Nesse cenário, privilegia-se hoje, a formação do professor-pesquisador, ou seja, ressalta-se a importância da formação do profissional reflexivo, aquele que pensa-na-ação, cuja atividade profissional se alia à atividade de pesquisa (PEREIRA, 2007, p. 41).

Com isso, analiso que além da preocupação conteudista, da organização dos currículos dos educandos e outras; a formação do professor apresenta-se como medida central de análise, o que possibilita o desenvolvimento do docente como sujeito que realiza suas ações de modo não robotizado. Tal fato reitera a importância das interpretações e reflexões constantes sobre a sua prática pedagógica.

Nesse enfoque, contextualizo a função reflexiva além da racionalidade técnica, na figura de um professor não somente como um ser que domina as matérias que leciona, mas também um indivíduo que deve refletir sobre suas ações, ponderá-las, modificá-las em relação aos papéis sociais desempenhados, confirmando que

[...] a situação da instituição escolar se torna mais complexa, ampliando a complexidade para a esfera da profissão docente, que não pode mais ser vista como reduzida ao domínio dos conteúdos das disciplinas e à técnica para transmiti-los. É agora exigido do professor que lide com um conhecimento em construção - e não mais imutável - e que analise a educação como um compromisso político, carregado de valores éticos e morais, que considere o desenvolvimento da pessoa e a colaboração entre iguais e que seja capaz de conviver com a mudança e a incerteza (LIMA, 2004, p. 118). 
Com essa reflexão histórica, embasada em um contexto mais amplo e repleto de debates, que relaciono a transformação de foco educacional, ocorrida nas décadas citadas; como uma medida que possibilitou um novo comportamento do profissional docente no Brasil. Impulsionando, nessa nova configuração de formação, o desenvolvimento do professor como "um profissional autônomo, que reflete, toma decisões e cria durante sua ação pedagógica, a qual é entendida como um fenômeno complexo, singular, instável e carregado de incertezas e conflitos de valores" (PEREIRA, 1999, p. 113).

Sendo assim, trago a importância da pesquisa narrativa como um método investigativo na percepção de Clandinin e Huber (2010), elaborada por meio da escrita de diários reflexivos na vivência do professor. Afinal, se não era mais a visão técnica o elemento fundamental da docência, o gênero diário precisa ser compreendido como o material reflexivo ao professor que carrega incertezas, problemas e questionamentos, embasado em sua própria atividade didática. Zabalza (1994) reforça a definição de diário "como é um instrumento para veicular o pensamento do professor que permite auto-explorar a ação profissional, auto-proporcionar feedback e estímulos de melhoria, e estudar o pensamento e os dilemas do professor a partir de sua perspectiva".

Nesse campo de análise, o diário é compreendido como uma produção intimista que possibilita a intensa análise da própria prática profissional, o que possibilita que o professor consiga desenvolver seu próprio objeto de estudo e de construções identitárias, bem como seja o responsável por retextualizar sua prática. Assim, o docente utiliza do espaço escolar como um campo de formação, segundo Reichmann (2007).

Após confirmar as percepções teóricas de Zabalza (1994) e Reichmann (2007), a respeito do diário como um gênero discursivo, reitero que esse gênero apresenta como objetivo o compromisso de enfatizar o discurso do próprio professor, o que torna possível, então, "através da interlocução mediada pela escrita, criar mecanismos e espaços de reflexão sobre teorias e práticas que constituem os modos individuais e coletivos de compreensão e produção/reprodução deste campo de trabalho" (SIGNORINI, 2006, p. 54).

\section{A Linguística Sistêmico-Funcional e o Sistema da Avaliatividade}

A Linguística Sistêmico-Funcional, doravante LSF, é compreendida como uma teoria semiótica responsável por dar visibilidade às concretas utilizações da linguagem, partindo das necessidades fundamentais de uso desse processo comunicativo envolto ao campo social. 
Como contextualiza Halliday (1994 apud ALMEIDA, 2010, p. 18), um elemento teórico fundamental, para esse foco de estudo, é o "uso da língua motivado pelas relações sociais".

Nessa lógica, ao analisar de forma epistêmica os termos que caracterizam a LSF, percebo que esses justificam-se na seguinte construção: "sistêmica" por razão de considerar a língua como "redes de sistemas linguísticos interligados" e "funcional”, pois, "explica as estruturas gramaticais em relação ao significado", segundo Fuzer e Cabral (2014, p. 19). Reafirmando a teoria de Webster (2009), Fuzer e Cabral (2014, p. 21) em que contextualizam "a linguagem como um recurso para fazer e trocar significados", tendo como base a vivência dos indivíduos em seus papéis sociais. Ademais, a linguagem é caracterizada, ainda, como "um modo de agir, de dar e solicitar bens de serviços e informações".

Além dessa definição, outros dois elementos são essenciais para o entendimento da teoria da Linguística Sistêmico-Funcional: texto e contexto. O texto, relacionado diretamente à linguagem, é defino por Gouveia (2008) como:

- O que produzimos quando comunicamos e interagimos;

- Falado ou escrito ou não verbal;

- Individual ou coletivo;

- Composto de apenas uma frase ou de várias (a extensão não é relevante)

- Uma coleção harmoniosa de significados apropriados ao seu contexto;

- Realizado por orações;

- Um processo contínuo de eleição semântica.

Todos os textos apresentam algum propósito de criação e são usados para um fim comunicativo que se relaciona ao contexto: de produção, de consumo e de circulação. Os quais apresentam, em ordem, quem produz, para quem se produz e a veiculação, visando chegar ao alvo comunicativo (FAIRCLOUGH, 2001).

Dado isso, classificada como uma construção social, a linguagem materializa-se em diferentes funções de uso, o que Halliday (1994) caracteriza como as "metafunções"; as quais são as manifestações linguísticas dos propósitos relacionados às intenções dos usuários desse sistema, subdividindo-se nas relações "compreender o campo (ideacional), relacionar-se com os outros (interpessoal) e organizar a informação (textual)", defendidas por Fuzer e Cabral (2014, p. 32).

Por meio dessa interação social, faço uso, nesse artigo, do Sistema da Avaliatividade como um recurso linguístico e metodológico para a discussão dos dados. Nesse âmbito, para Vian Jr. (2010, p. 25), a Avaliatividade “está relacionada a todo o potencial que a língua 
oferece para [...] expressarmos pontos de vista positivos ou negativos" por meio do uso, teórico, da metafunção interpessoal. Essa é responsável por categorizar a interação entre os participantes de um contexto comunicativo que desenvolve, como objetivo, a identificação da avaliação presente na linguagem.

Martin e White (2005) reconhecem a subdivisão de três subsistemas que compõem a Avaliatividade: a Atitude, o Engajamento e a Gradação. Desses, a atitude está relacionada à manifestação de emoções e percepções dos acontecimentos. Já o engajamento estabelece a análise dos recursos discursivos que são necessários na relação entre as vozes dos falantes e, por fim, a Gradação refere-se aos recursos utilizados na produção textual.

A análise desenvolvida, no presente artigo, está centrada no subsistema da Atitude pelo fato de que as construções linguísticas, dos diários, são permeadas de emoções positivas ou negativas referentes à nova situação profissional vivenciada por mim. Esse sistema se subdivide em três categorias, como afirmam Almeida e Vian Jr. (2018), “de afeto, julgamento e apreciação. Todos eles envolvem sentimento, mas o julgamento e a apreciação são disposições das emoções que foram institucionalizadas para que pudéssemos entrar nas comunidades uns dos outros". Nessa configuração, o afeto

manifestado de forma explícita (representado em nível lexical através de adjetivos, verbos, advérbios e nominalizações) ou implícita (realizado mesmo quando não há o léxico avaliativo por meio dos significados ideacionais), tem a função de expressar linguisticamente as emoções no discurso. (OLIVEIRA, 2014, p. 252).

Ainda nas categorias, identifico, com base em Almeida e Vian Jr. (2018) e Oliveira (2014) que o Julgamento se encontra relacionado à atitude comportamental, isto é, estratégias comunicativas permeadas por organizações sociais, tais como a igreja e o Estado. Não obstante, a Apreciação retoma a teorização de avaliação sobre o fato de atribuição de valor no âmbito das relações estéticas, desenvolvendo o foco para o objeto ou instituição em consideração.

\section{Metodologia e a construção dos diários}

A pesquisa que fundamentou este artigo tem como suporte metodológico o embasamento qualitativo (FLICK, 2009), especificamente no enquadramento do estudo de caso (TELLES, 2002) por meio da escrita e análise dos diários reflexivos, escritos por mim, durante as primeiras aulas como professor de Língua Portuguesa do Ensino Superior. 
Reafirmo o meu interesse em construir análises das produções discursivas por dois aspectos que julgo importantes: promover a reflexão sobre o motivo da minha rápida contratação como professor universitário, visto que estava com 22 anos e sem nenhum curso acabado de pós-graduação e quais desafios emocionais encontrei, uma vez em sala de aula; com alunos dos cursos de Administração e Ciências Contábeis.

Fundamentado em Telles (2002, p. 108), confirmo a contextualização de que

os estudos de caso, frequentemente descritivos (mas, também, podendo ser narrativos), são utilizados quando o professor-pesquisador deseja enfocar um determinado evento pedagógico, componente ou fenômeno relativo à sua prática profissional”.

Isso posto, a produção de oito diários foi realizada de acordo com as ações desempenhadas no decorrer do processo seletivo para a vaga de professor universitário, em momentos distintos: a aula teste, a contratação como professor na instituição do Ensino Superior e a primeira semana de aula nos cursos supracitados. Destarte, a escrita foi desenvolvida em um período médio de 15 dias, durante o segundo semestre do ano de 2018. Além disso, a análise dos dados foi fundamentada na Linguística Sistêmico-Funcional, correlacionando-se ao Sistema da Avaliatividade, a partir de critérios teóricos do subsistema da Atitude.

\section{Discussão dos dados}

Nesta seção, apresento e discuto trechos significativos no que diz respeito à manifestação de afeto, retirados dos meus dois primeiros diários reflexivos. Desse modo, como critério de organização, estabeleci a ordem da análise em momentos cronológicos: 1) a tensão na aula teste, 2) a expectativa na contratação como professor do Ensino Superior, buscando responder as perguntas de pesquisa: a) quais foram as principais preocupações expostas nos diários? b) como essas preocupações se realizam linguisticamente?

\section{1) A tensão na aula teste}

\section{Excerto a)}


Hoje, dia 11/07/2018, acabei de passar por uma aula teste para dar aulas no Ensino Superior em uma faculdade da Região do Sul de Minas. A aula em si não me amedrontou, mas o fato de estar concorrendo para ser professor universitário me deixa receoso.

Nesse trecho, os vocábulos "amedrontou" e "receoso" retomam uma avaliação sentimental afetiva de caráter positivo, já que o primeiro termo é precedido por "não", e, depois, negativo pelo contexto em que está inserido. É possível inferir, com isso, que a primeira preocupação contextualizada interliga-se à problemática da inserção, ainda hipotética, no Ensino Superior. O trecho "A aula em si não me amedrontou" confirma a minha segurança enquanto docente, todavia, concorrer para ocupar um novo espaço profissional não era uma ação confortável.

É válido retomar a importância da escrita dos diários reflexivos, uma vez que, para Dias (2013), essa prática é um exame crítico da atividade docente, o que pode ser considerado como um espaço de interpretações e reflexões que utilizei, a priori, para descrever a insegurança de uma ação que acabara de realizar.

\section{Excerto $b$ )}

É uma mistura de felicidade e medo, por ora, não consigo explicar melhor. A banca estava marcada para às 7h40min, como cheguei mais cedo, pude perceber que pessoas, aparentemente mais velhas do que eu, estão concorrendo comigo. Nesse momento que a alegria foi embora, restava somente o medo de ser jovem e estar em um contexto que não parecia ser meu.

A situação descrita era propícia para o sentimento de incerteza, contido no fragmento acima, pois, em "alegria foi embora", fica perceptível a relação de Avaliatividade por meio do uso da noção de afeto, sendo esse o centro das atitudes que expressamos. (VIAN JR, 2009).

Logo, ao não saber qualificar os sentimentos momentâneos, perceptíveis nas construções: "É uma mistura de felicidade e medo.", "aparentemente mais velhas do que eu" reforço a insegurança que apresentava durante a situação. Dito isso, essa vertente de análise encontra-se teoricamente relacionada ao que Zabalza (2004) categoriza como a documentação de emoções e sentimentos em relação a prática docente, mesmo que, nesse caso, seja uma fragmentação da atividade de lecionar em uma aula teste.

\section{2) A expectativa na contratação como professor do Ensino Superior}




\section{Excerto c)}

Logo depois de receber a ligação, na qual descobri que já posso me sentir como um professor universitário, só tenho dizeres felizes para descrever nesse texto. Não tenho medo das aulas, não tenho receio do ofício de ser professor. Mais do que nunca, sinto-me bem para começar esse novo projeto em minha vida: ser professor do Ensino Superior.

O excerto que discuto, nesta subdivisão, faz referência a um acontecimento inovador em minha vida profissional. Nesse viés, linguisticamente, por ora, não há nenhuma marca textual de receio ou medo de acontecimentos vindouros, relacionados à atividade nova que executaria. Bem como certifica Tápias-Oliveira (2013), os textos em formato de diário podem ajudar a compreender a construção identitária profissional relacionada, na minha escolha lexical, à confiança que apresento em exercer a função de professor.

Ainda nessa perspectiva, os trechos: "só tenho dizeres felizes para descrever nesse texto" e "Não tenho medo das aulas, não tenho receio do ofício de ser professor" comprovam, por meio de orações sentimentais positivas, a relação afetiva e de interesse que vivenciava com o momento de certeza da contratação como professor universitário e com o fato de gostar de ser um docente. Aliado a isso, Martin e White (2005, p. 42) confirmam que o "afeto diz respeito ao registro positivo e negativo de sentimentos: sentimo-nos felizes ou tristes, confiantes ou ansiosos, interessados ou entediados".

\section{Excerto d)}

Passado o momento de euforia inicial, a ficha está "caindo". E agora me pergunto: que professor quero ser no Ensino Superior? Estou com dúvidas sobre as minhas aulas futuras. Percebo que sentimentos de incerteza, do início da carreira, voltaram! Estou me sentindo amedrontado com o modo de lidar com discentes dos cursos de Administração e Ciências Contábeis.

Oliveira (2014) defende que o subsistema afeto está presente nos enunciados em que as avaliações são direcionadas e afetam diretamente ao avaliador. Nesse ínterim, a preocupação contextualizada na parte: "E agora me pergunto: que professor quero ser no Ensino Superior?" apresenta uma construção de dúvida que remete a um sentimento de insegurança centralizado no verbo "pergunto".

Revista Devir Educação, Lavras, vol.4, n.2, p.314-327 jul./dez., 2020. 
Não apenas, retiro como análise o trecho: "Estou me sentindo amedrontado" que retoma uma percepção de afeto sentimental negativo. Essa manifestação, na descrição do que sentia, não é algo deslocado desde o início da construção dos diários. Fato é que o sentimento mais pertinente nesses textos é o de insegurança expressa por meio da preocupação com acontecimentos futuros. Esses relacionados a atividade de ser docente universitário.

Por conseguinte, esse trecho retoma a mais significativa função dos diários para a descrição do momento que vivenciei. De tal forma que Clandinin e Huber (2010) reafirmam a pesquisa narrativa como uma maneira de pensar sobre a própria experiência através de um olhar investigativo.

\section{Considerações finais}

A escrita intimista, voltada para as interpretações do próprio sujeito, é necessária para o profissional docente, visto que as atividades desempenhadas, por esse, são demasiadamente relacionadas a uma gama de sentimentos e emoções que precisam ser desvendadas por meio de análises e reflexões.

Meu objetivo inicial foi o desenvolvimento de um trabalho voltado para a minha experiência durante o processo seletivo para ocupar uma vaga como professor do Ensino Superior. O tópico principal de investigação centrou-se nas preocupações que perpassavam esse processo em ser um professor universitário.

Ao relacionar, então, as teorias advindas das publicações sobre o uso de diários reflexivos com a minha própria prática de pesquisa, foi possível perceber a concreta importância em fazer uso dessa metodologia de escrita desafiadora, como um sujeito formado e em constante processo de formação como professor.

O suporte analítico embasado na Linguística Sistêmico-Funcional possibilitou que as interpretações das estruturas frasais, contidas nos diários, solidificassem aquilo que já sentia, a mesclagem de emoções que se originavam de uma nova experiência profissional e os significados existentes a partir desse cenário. Ratifico, por esse motivo, que a docência está intrinsicamente relacionada a uma vivência sentimental, cercada de significados nas experiências que nós, professores, partilhamos diariamente. 
Dessa forma, por essa razão de importância, na elaboração de uma pesquisa voltada para o sujeito, espero contribuir para o processo de formação de futuros professores, principalmente os mais jovens, que têm o objetivo de se tornarem docentes universitários. Por fim, espero que a minha pesquisa possa desenvolver, em educadores, o anseio pela produção de textos reflexivos para que possam investigar as suas próprias práticas e compreendê-las de um modo mais significativo.

\section{Referências bibliográficas}

ALMEIDA, F. Ap. S. D. P.; VIAN JR., O. Estudos em Avaliatividade no Brasil: panorama 2005-2017. Signótica, Goiânia, v. 30, n. 2, p. 273-295, abr./jun. 2018.

ALMEIDA, F. Ap. S. D. P. Atitude: afeto, julgamento e apreciação. In: VIAN JR. O.; SOUZA, A. A. de; ALMEIDA, F. Ap. S. D. Pa. (Orgs). A linguagem da avaliação em língua portuguesa. Estudos sistêmico-funcionais com base no Sistema de Avaliatividade. São Carlos: Pedro \& João Editores, 2010b.

ALMEIDA, F. Ap. S. D. P. A avaliação na linguagem. Os elementos de atitude no discurso do professor. São Carlos: Pedro \& João Editores, 2010a.

CLANDININ, D. J.; HUBER, J. Narrative inquiry. In: BAKER, McGaw B., E.; PETERSON, P. P. (Eds.), International encyclopedia of education. 3. ed. New York, NY: Elsevier. 2010.

CORACINI, M. J. Discurso e escrit(ur)a: entre a necessidade e a (im) possibilidade de ensinar. In: Eckert-Hoff, Beatriz \& Coracini, Maria José. Eds. Escrit(ur)a de si e alteridade no espaço papel-tela. Campinas: Mercado de Letras. 2010.

FAIRCLOUGH, N. Discurso e mudança social. Brasília: Universidade de Brasília, 2001.

FUZER, C. \& CABRAL, S. R. S. Introdução à Gramática Sistêmico-Funcional em Língua Portuguesa. Campinas: Mercado de Letras, 2014.

FLICK, U. Introdução à pesquisa qualitativa. 3. ed. Porto Alegre: Artmed, 2009.

GOUVEIA, C. A. M. Textos, análise e interpretações: a Linguística Sistêmico-Funcional. Palestra proferida em 06/10/2008. Pelotas: Universidade Federal de Pelotas (UFPel); Universidade Católica de Pelotas (UCPel), 2008.

HALLIDAY, M. A. K. \& WEBSTER, J. Orgs. Continuum companion to systemic functional linguistics. London/New York: Continuum, 2009.

HALLIDAY, M. A. K. An introduction to Functional Grammar. 2. ed. London: Edward Arnold, 1994.

LIMA, C. V. A. "Eu faço o que posso": experiências, agência e complexidade no ensino de língua inglesa. 2014. 234 f. Tese (Doutorado) - Curso de Linguística Aplicada, Programa de 
Pós-graduação em Estudos Linguísticos, Universidade Federal de Minas Gerais, Belo Horizonte, 2014.

MACHADO, A. R. O diário de leituras. A introdução de um novo instrumento na escola. São Paulo: Martins Fontes, 1998.

MAGALHÃES, J. R. da S. Letramentos digitais e ensino-aprendizagem de língua inglesa: reflexões acerca do processo crítico-reflexivo do aluno em sala de aula. in: Seminário de formação de professores e ensino de língua inglesa, 4., 2018, São Cristóvão, SE. Anais eletrônicos [...]. São Cristóvão, SE: LINC/UFS, 2018. p. 154-167.

MARTIN, J.R. e WHITE. The language of evaluation: Appraisal in English. London: Palgrave Macmillan, 2005.

MENEGASSI, R. J. Professor e escrita: a construção de comandos de produção de textos. Trabalhos em Linguística Aplicada, Campinas, 2003.

OLIVEIRA, D. M. O Sistema de Avaliatividade: aspectos teóricos e práticos. Itabaiana: Gepiadde, Ano 08, Volume 15 | jan./jun. de 2014.

PEREIRA, J. E. D. Formação de professores: pesquisa, representação e poder. Belo Horizonte: Autêntica, 2007.

PORTER, P. A.; GOLDSTEIN, I. M.; LEATHERMAN, J. \& CONRAD, S. An ongoing dialogue: learning logs for teacher preparation. In: J.C. RICHARDS \& D. NUNAN (Eds.). Second Language Teacher Education, Cambridge: Cambridge University Press, 1990.

REICHMANN, C. L. Ensinar, escrever, refazer(-se): um olhar sobre narrativas docentes e identidades. In: PEREIRA, R. C. M.; ROCA, P. (Org.). Linguística aplicada: um caminho com muitos acessos. São Paulo: Editora Contexto, 2009.

SIGNORINI, I. O gênero relato reflexivo produzido por professores da escola pública em formação continuada. In Gêneros Catalisadores: letramento e formação de professores. São Paulo: Parábola, 2006.

SILVA, M. A. Diários reflexivos e avaliação formativa: um olhar sobre a prática do professor. Domínios de Lingu@gem, v. 8, n. 1, p. 541-554, 30 jun. 2014.

TÁPIAS-OLIVEIRA, E. M. Quem sou eu, Quem é você? Imagens dos interlocutores do/no diário e a construção identitária. In: REICHMANN, C. L. (Org.). Diários reflexivos de professores de línguas: ensinar, escrever, refazer(-se). Campinas: Pontes, 2013.

TELLES. J. A. "É pesquisa, é? Ah, não quero, não, bem! Sobre pesquisa acadêmica e sua relação com a prática do professor de línguas. Revista Linguagem e Ensino. Editorial, 2002.

VIAN JR. O. O Sistema de Avaliatividade e os recursos para gradação em Língua Portuguesa: questões terminológicas e de instanciação. DELTA vol.25 n.1, São Paulo, 2009.

VIAN JR. O.; SOUZA, A. A. de; ALMEIDA, F. A. S. D. P. (Orgs). A linguagem da avaliação em língua portuguesa. Estudos sistêmico-funcionais com base no Sistema de Avaliatividade. São Carlos: Pedro \& João Editores, 2010. 
ZABALZA, M.A. Diários de aula. Contributo para o estudo dos dilemas práticos dos professores. Porto: Porto Editora, 1994.

ZABALZA, M.A. O ensino universitário: seu cenário e seus protagonistas. Porto Alegre: Artmed, 2004.

Recebido em: 30/08/2020

Aprovado em: 03/10/2020 